or another patient who, acting without suggestion, may give the first elue. Sham being suspected, it is, then, a matter of long-continued observation and possibly several periods of hospital residence before the mental status can be definitely determined.

A diagnosis of malingering should not be made until all reasonable doubt of insanity has been eliminated. Even then the underlying condition must be studied for proper classification. 'The constitutional defect may be of sufficient degree to classify in the hospital, or there may be a definite psychosis in the background.

'The importance from the legal, social and medieal points of view is equally great. To mistake a genuine psychosis for shamming is an injustice, and might happen to any of us. Although eomparatively few mistakes are made by the experienced observer, the fact remains that the determination of the true mental status is oftentimes extremely diffieult, particularly in criminal eases, and that judgment is not infrequently passed by those lacking qualifications and training.

I feel that in all instances of doubt, commitment to a hospital for the determination of the insanity, as provided for by statute, is most essential, not only for the protection of those truly insane, but for the elimination, if possible, of the malingerer, and incidentally for a study of the defeet which is the fundamental basis of the deception. The latter may be of sufficient degree to absolve even the malingerer from being stigmatized a criminal.

\section{TRAUMATIC INJURIES OF THE KIDNEYS}

By Frank Warner, M.D., F.A.C.S., Columbus, Ohro.

A young man, twenty-five years of age, was thrown against a cooking range at the time of a derailmont of a rapidly-moving passenger train. In alighting, his back, in the region of the right kidney, struck the range. No special soreness resulted from the fall, but the next day he noticed blood in the urine. This was perceptible only for the one day, and then only in small amount. The following day he consulted me, but stated there was no longer any blood came away with the urine; however, an examination revealed, through the microscope, $\mathrm{n}$ small amount of blood present, and a little more than a trace of albumen in the urine. This condition of affairs continued for one weok, when the trouble gradually subsided, having entirely disappeared at the end of ten days. Rost was the only treatment employed.

From the fact that the trouble so quickly subsided, one would be led to believe that nothing more than a contusion of the right kidney had occurred. None of the severer symptoms that go with more serious injuries of the kidneys was present.

Even these slight contusions of the kidneys must not be too lightly regarded. Murphy has pointed out the fact that any bruised tissue frequently becomes a prey to infective germs of one type and another. So, one needs a little time following these injuries to say with positiveness that no ill results will follow.

The purpose of the report of this mild case of traumatic hematuria is to call attention to the fact that slight contusions of the kidneys may escape observation unless care is exereised to diannose them. It is not improbable that some of the injuries that are regarded as contusions of the museles of the back have extended beneath the muscle walls to the kidneys themselves. While rest is valuable treatment for contusions of the museles of the back, it becomes doubly important when the kidneys themselves are involved in the injured tissue. Besides, the complications which may subsequently arise, even in slight injuries to these organs, it behooves us to be alert and not overlook the true pathology which exists. This can be done if one will take the trouble to examine the urine, in addition to the back, at the seat of the contusion. Not until then can the diagnosis be correctly made nor the prognosis satisfactorily given.

Tnjuries to the kidneys are quite as ant to result, where the violence has been sustained by the ahdomen rather than the back.

What scems to be a slight contusion of the kidney at the time of the accident, may turn out to be a severe laceration of the renal tissue. Even after a severe injury to these organs, blood may not appear in the urine, for the time at least, owing to the fact that the ureter has been blocked hy a elot of blood. Generally, however, this elot is soon passed down the ureter, frequently with the pain of a calculus moving in this tube. But there are other symptoms that point to the seriousness of the injury, and the situation of the blow received will indieate the probable organ involved.

All grades of injury occur to the kidneys as the result of accidents, from the mildest contusions to the severest lacerations.

It usually requires a very considerable force to injure the kidneys, owing to their protected position, situated as they are beneath the ribs.

Injuries of the kidneys that result from extermal blows, usually depend upon falls from a height, striking upon the back or abdomen, weights falling upon the patient, kicks of a horse, the ball of switeh stand striking one on a moving train, crowding an individual between rigid moving boties, as a train and platform; or, being struck by a pole of a wagon, hit by a base ball, etc.

If only a contusion of the kidney or kidneys results from the violence, a slight heinaturia, without other symptoms, as in the case here related, may be the sole proof that injury has been sustained. Generally, however, pain in the lumbar region will be associated with the hematuria. Laceration of the kidney substance will, 
however, give mole pronounced symptoms, depending upon the extent of the laceration in part, and the amount of associated injury. If excessive hemorrhange is present, it will soon lead to ummistakable symptoms, frequently producing collapse, in addition to the other usual symp)toms of concealed hemorrhage.

Shock is a prominent associate of severe kidney injuries, as might well be expected, for the severer kidney injuries have been inflicted by a force that has only partly expended itselt on these organs, eonsequently other complicating injuries are present which adds to the shock of the kidney injury.

Anuria is frequently associated with the severer injuries of these organs.

Just as injuries of any part of the abdominal cavity give rise to mausea and vomiting, so here similar symptoms are present in lacerations of the renal substance.

Anywhere from a few days to a few weeks following the receipt of the injury, an elevated temperature, leucocytosis, and the presence of septie symptoms in general may announce the infection of the lacerated kidney. 'This frequently calls for prompt nephrectomy, just as a severe laceration of the organ may demand similar treatment.

In the milder cases of kidney injuries, rest is the sole treatment needed. Where they are more decisive, the entire situation must be canvassed, for an exploratory incision may be demanded to deal with the injured organ as necessity seems to dictate. It may be found that controlling hemorrhage and suturing the capsule will prove all that is necessary, but, on the contrary, one may find an amount of laceration of the kidney substance which demands a nephrectomy be done.

While contusions and superficial lacerations usually recover, the severer lacerations tend in the direction of death, either from hemorrhage or peritonitis, unless a nephrectomy is undertaken early enough to circumvent this untowardi event. Even without operation, however, recoveries have taken place after the most extensive lacerations.

If a fatal result does not follow the shock of the injury, hemorrhage, or peritonitis, a later line of dangers comes along to complicate the prognosis. Septicemia, toxemia, urinary extravasation, cystitis, multiple renal or perirenal abscesses, etc., may arise to produce death unless measures are instituted to prevent it.

In an analysis of 67 collected cases of deaths jesulting from traumatic injuries of the kidneys, Morris found 30 deaths due to hemorrhage and 27 to suppuration or subsequent infection. (Morris, vol. i, p. 179).

Kidney lacerations and contusions are often associated with other injuries, as might well be expected from the amount of force that is frequently expended on the patient receiving them.
Fracture of the neighboring ribs, with a fragment jabbing into the kidney, a fractured spine, or rupture of the liver and perhaps some other abdominal organ, is a not uncommon oceurrence in these injuries. Such complications were present in twelve out of seventeen deaths from kidney lacerations collected by keen. (Vol. iv, ]. 214).

In looking over the literature, it is evident that 110 one surgeon sees many cases of severe injuries of the kidneys. Ont of $77+1$ injuries of all types, Kuster, in his elinies at Basel and Berlin, only encountered ten cases of lacerated kidners. Of 2610 antopsies, he found 13 injuries of the kidneys, one a penetrating wound. 'Three of these calses were evidently encountered after death, as they are not included in the cases of injuries treated or diagnosed in his alinic.

Kuster showed, experimentally, that many lacerations of the kidneys were the result of hydrostatice pressure.

Rausahoff quotes Dolbert's eollected statisties of 319 cases in which 225 were not operated upon, with 103 deaths. lifty cases treated by suture, packing, or partial nephrectomy, 2 deaths occurred. In Watson's 273 collected cases unoperated upon, 81 died. In 93 cases treated by conservative operations, 7 died. In 115 nephrectomies, 25 died.

Comell reports five cases of kidney laceration operated upon by him, four of a mild subparietal type and one severe. The four mild cases recovered; the severe injury was not operated on until ten days after the recipt of the injury, and the patient died.

To know when to operate on an injured kidney is always a difficult, and frequently uncertain, matter. But Keen has shown that only half the danger exists in operating on the kidney early, that obtains later in the history of the injury. When a hematuria continues, a hematoma forms in the region of the kidney, and if it seems to be increasing in size, together with symptoms of concealed hemorrhage, it is far better to operate then, under good conditions, than wait until the risk is greatly increased. Even if the hematoma spoken of does not appear, the hemorrhage that is taking place may be dissecting up tissues for a considerable distance, when the evidence of concealed hemorrhage must take the place of evidence of a hematoma. To wait too long only makes the prognosis more grave. Under modern aseptic precautions the danger of an exploratory operation on the kidney is not great if it is undertaken before too extensive hemorrhage has occurred or septic infection has taken place.

\section{REFERTNCEB,}

Morris, Henry, F.R.C.s.: Surgienl Disenses of the Kidney. lieen's Surgery. Vol. Iv.

Chetwood: The Prnctice of Urolngy.

(initeras: Urology.

Murnhy, John B.: Clinics.

Jambenn nnd Steward: The Operations of Sureery.

Conmell, F. Ciregory, M.D.: Strk.. Fyn., and Obst., June, 1916. 